\title{
The Influence of a Pilot Nutrition Education Program on Dietary Knowledge among Undergraduate College Students
}

\author{
Geraldine Napoleone Pires ${ }^{1}$, Amy Pumerantz ${ }^{2}$, Lawrence K. Silbart ${ }^{1}$, and Linda S. Pescatello ${ }^{3}$ \\ Department of Allied Health Sciences ${ }^{1}$, Student Health Services ${ }^{2}$, and Department of \\ Kinesiology, University of Connecticut
}

\begin{abstract}
Objective and Participants: The objective of this study was to determine if a nutrition education program, Everyday Healthy Eating on Campus (EHEC), resulted in positive healthy eating perceptions and behaviors among 103 undergraduates. Methods: Students from eight dormitories $(n=42)$ and five classrooms $(n=61)$ completed a shortened Diet and Health Knowledge Survey (DHKS) prior to and one month after EHEC. Another 153 students from eight dormitories $(n=56)$ and five classrooms $(n=62)$ were the comparison group. Results: Students that completed EHEC increased their perceived value of eating a diet moderate in salt and sugar, low in saturated fat, adequate in fiber, eating a variety of foods, and consuming a diet with adequate carbohydrate containing foods $(\mathrm{p}<0.05)$. No significant differences were found in comparison group surveys ( $p>0.05$ ). Conclusions: A simple one session college nutrition education program focusing on specific campus dining strategies appears to positively affect undergraduate students' perceived value of healthy eating.
\end{abstract}

(C) 2008 Californian Journal of Health Promotion. All rights reserved.

Keywords: campus dining, nutrition education, college students

\section{Introduction}

The American College Health Association (ACHA) has identified "Nutrition \& Overweight" as one of the major Focus Areas of Healthy Campus 2010, making it a national objective to improve the diet patterns of college students. One goal of this focus area is to increase the proportion of college students who receive information from their college about dietary behaviors and prevention through nutrition from a baseline of 32.7 percent in 2000 to a target of 55.0 percent in 2010 (ACHA, 2007). Though the "Freshman 15" has gained acceptance as a well-known myth, the average three-pound increase in weight and 0.7 percent body fat gain during the first year of college is concerning (Anderson, Shapiro, \& Lundgren, 2003; Delinsky \& Wilson, 2008; Hoffman, Policastro, Quick, \& Lee, 2006). About four in ten college students are overweight (body mass index $[\mathrm{BMI}] 25-29.9 \mathrm{~kg} / \mathrm{m} 2)$ or obese $(\mathrm{BMI} \geq$ $30 \mathrm{~kg} / \mathrm{m}^{2}$ ) (ACHA, 2007). Moreover, 93.3 percent consume less than the recommended five daily servings of fruits and vegetables (ACHA, 2007), while one study found college students' reported consumption of unhealthy items such as cakes, pies, doughnuts, cookies, and ice cream to be as often as one to two times per day (Clement, Schmidt, Bernaix, Covington, \& Carr, 2004).

College nutrition interventions enable positive dietary changes (Kolodinsky, Harvey-Berino, Berlin, Johnson, \& Reynolds, 2007; Collision, Kuczmarski, \& Vickery, 1996; Conklin, Lambert, \& Cranage, 2005). When nutrition information was provided on a university menu to Texas A\&M college students $(n=43$, mean age $19.6 \pm 1.3 \mathrm{yr}$ ), 30 percent of students who followed the nutrition facts lost weight (Kubena \& Carson, 1988). In fact, students who took advantage of a modified menu to obtain caloric information had a lower energy intake (734 \pm $225 \mathrm{kcal})$ than students who did not $(930 \pm 419$ kcal) (Kubena \& Carson, 1988). These results suggest that nutrition interventions at the point 
of purchase may create an awareness that results in healthier eating.

More aggressive interventions providing semester long courses as a means to dispense basic nutrition information and healthy eating strategies also have been found to impact dining patterns (Mazier \& McLeod, 2007; Matvienko, Lewis, \& Schafer, 2001). Matvienko et al. (2001) administered a nutrition course to 40 female freshmen at Iowa State University, and reported that students in the intervention group with $\mathrm{BMI} \geq 25 \mathrm{~kg} / \mathrm{m}^{2}(\mathrm{n}=11)$ lost an average of $1.4 \mathrm{~kg}$ of body weight after participating in a nutrition course that stressed basic principles of human physiology, energy metabolism, and genetics compared to students in the comparison group with a BMI $\geq 25 \mathrm{~kg} / \mathrm{m}^{2}(\mathrm{n}=6)$ who gained an average of $9.2 \mathrm{~kg}$.

In a study by Misra (2007), nutrition education and attitude predicted label reading behavior, suggesting that attitude mediates the relationship between nutrition knowledge and dietary behavior. Thus, it may be advantageous for nutrition education programs to target participant attitudes in order to have an impact on positive behavior change.

Dietary nutrition education programs appear to impact college students' knowledge, attitudes and behaviors toward healthy eating. Yet, research examining the effectiveness of such programs is limited. Therefore, we designed, implemented, and evaluated a nutrition health promotion program entitled, Everyday Healthy Eating on Campus (EHEC). The purpose of EHEC was to enhance nutrition awareness and bring about positive changes in knowledge and consumption of junk foods among college underclassman who were dining on campus. EHEC was a one hour session designed and taught by a Registered Dietitian (RD) who provided students with specific healthful eating strategies for campus dining. We hypothesized EHEC would encourage positive eating awareness, as assessed by the Diet and Health Knowledge Survey (DHKS) (U.S. Department of Agriculture [USDA], 1995), among 103 undergraduate students 18-24 years of age who completed EHEC.

\section{Methods}

\section{Participants}

Participants included a convenience sample of university students living in dormitories and enrolled in first-year courses in the spring semester. Study investigators sent flyers that discussed the study and requested participation to University Community Assistants (CA's). Eight CAs contacted the RD to hold EHEC for students residing in their dormitory. Students in these dormitories who chose to attend EHEC served as the intervention group. Students in these dormitories who did not attend the EHEC were used as comparison participants. In addition, study investigators contacted course instructors via intercampus mail and spoke with program directors of first-year courses to recruit students. Five first-year course instructors agreed to allow the RD to administer EHEC to students in their classes. Another five first-year course instructors agreed to allow their classes to serve as comparison participants.

Students in five first-year courses $(\mathrm{n}=81)$ and eight dormitories $(n=85)$ participated in EHEC $(\mathrm{n}=166,101$ Female). Another 153 students (53 percent Female) enrolled in five first-year courses $(n=70)$ and eight dormitories $(n=83)$ served as the EHEC comparison group.

\section{Study Overview}

The study design overview is depicted in Figure 1. Each subject read a study information sheet which contained a description of the research project that was approved by the Institutional Review Board at the University of Connecticut. All subjects provided verbal informed consent before participating in the study. EHEC was designed, conducted and evaluated by a RD to focus on healthy meal strategies to use in campus dining halls. To assess dietary attitude and behavior changes, all participants completed a short-form of the DHKS (USDA, 1995) preand one month post-EHEC. Subjects participated in a campus meal plan and did not receive compensation for participating in the study. 


\section{Procedures}

\section{The Diet and Health Knowledge Survey (DHKS)}

Participants were asked to complete an abbreviated version of the DHKS (USDA, 1995) prior to the start of EHEC, and approximately one month later. The original DHKS had 149 questions to obtain information on participants' knowledge, attitudes and behaviors regarding nutrition (USDA, 1995). We chose the DHKS because it has been shown to be a valid and reliable instrument for evaluation of adults' (specifically, Americans who are at least 20 years of age) nutrition knowledge, nutritionrelated psychosocial factors, and dietary behaviors (Sapp \& Jensen, 1997; Obayashi, Bianchi, \& Song, 2003). York-Crowe, White, Paeratakul, and Williamson (2005) condensed the original DHKS from 149 questions to 12factor groupings that could be used individually to examine knowledge of particular nutritional constructs (e.g., factor (1) is perceived value of healthy eating, and factor (2) is use of food labels). For our study, we chose six of these 12 factor groupings including: factor (1), perceived value of healthy eating; factor (3), consumption of low-fat/low-calorie foods; factor (5), perception of adequacy of intake; factor (6), intake of added fats; factor (11), avoidance of extra fat; and factor (12), consumption of junk food. Questions from these six factors were chosen because we developed EHEC to focus on the perception,knowledge and consumption of junk foods, and these factors were the most appropriate to assess these outcomes in our environment.

For questions regarding students' responses to factor (1), perceived value of healthy eating, possible responses included very important, somewhat important, not too important, and not at all important. For questions regarding factor (3), consumption of low-fat/low-calorie foods, factor (6), intake of added fats, and factor (11), avoidance of extra fat, possible responses included always, sometimes, rarely, and never. For questions regarding factor (5) perception of adequacy of intake, possible answers were too low, too high, and about right. Lastly, responses for questions regarding factor (12) consumption of junk food, were less than once/week, one to three times/week, four to six times/week, and seven or more times/week. The six-factor DHKS was administered before and one month after EHEC to both the EHEC and comparison groups.

\section{The Everyday Healthy Eating on Campus (EHEC) Intervention}

Two study investigators who were RDs designed EHEC, and one of them delivered EHEC. The conceptual framework for the intervention was based on the Dietary Guidelines for Americans (U.S. Department of Health and Human Services [USDHHS] \& USDA, 2005). Key concepts of this framework incorporated into EHEC included the meaning of a healthy diet, portion control, and the maintainence of a healthy weight with a balance of proper nutrition and physical activity.

EHEC encouraged students to utilize three major strategies when dining on campus. These strategies included: 1) identification of dining hall layout; 2) utilization of the Plate Model, which is a visual method used to help students eat the recommended amounts of carbohydrates, fats, and proteins at each meal (Camelon et al., 1998) and; 3) selection of proper portion sizes. Each strategy was coupled with one or more activities throughout the one-hour EHEC lecture for students to receive an experiential learning experience (Kolb \& Fry, 1975). The RD instructor began EHEC by asking student volunteers to share their ideas of healthy eating, and where they believed they would find healthy food items in the dining hall. A "healthy diet" was identified as one that emphasizes fruits, vegetables, and whole grains, and fat-free or low-fat milk and milk products; lean meats, poultry, fish, beans, eggs, and nuts; and low amounts of saturated fats, cholesterol, salt (sodium), and added sugars (USDHHS \& USDA, 2005).

After discussing what a "healthy diet" encompassed, the RD introduced the first strategy students could use when trying to eat healthfully on campus - being aware of the dining hall food and beverage layout. For 
example, students were made aware of where to find certain food items such as the fruit basket and salad bar so that they could then navigate to those stations in an effort to enhance fruit and vegetable intake. This strategy also emphasized the importance of knowing the location of the fried food and dessert sections in order to limit the frequency of visits to those areas, and reduce intake of calorically dense, less nutritive foods.

The second EHEC strategy utilized a simple and effective meal planning tool known as the "Plate Model" (Camelon et al., 1998). Students were asked to draw a picture of their typical lunch tray. This activity allowed students to compare the lunch tray they constructed with the ideal meal tray of the second strategy. This strategy was implemented to help foster the students' ability to acquire the recommended amounts of carbohydrates, fats, and proteins at each meal. The RD instructed students to fill one-half of the plate (approximately one cup) with non-starchy vegetables such as green beans, broccoli, Brussels sprouts, cauliflower, or squash, and another quarter of the plate with a serving of lean protein such as fish, skinless poultry, tofu, low-fat cheese, or eggs. The last quarter of the plate was to be filled with a carbohydrate source such as baked or mashed potato, rice, pasta, or bread. Students then worked in groups and used food models (National Dairy Council@2007, Rosemont, IL) to create healthy meals that followed the Plate Model strategy (Camelon et al., 1998).

The third EHEC strategy focused on portion control. The RD asked two student volunteers to pour a bowl of cereal and a glass of juice as they typically would in the dining hall. The bowl and glass represented those used in the university's dining hall. Next, the RD reviewed proper portion sizes of some typical food types and showed the students visual aids of everyday items that could be used to estimate portion sizes (e.g., $3 \mathrm{oz}$ of meat $=$ size of a deck of cards, tennis ball $=$ one cup of cereal, and golf ball = two tablespoons peanut butter). An open discussion followed allowing students to share what they believed was one portion size of cereal or of juice. After this discussion, two student volunteers were asked to measure out one serving of cereal and one serving of juice using measuring cups. These measurements were compared to the ones made before the portion size discussion.

In the last few minutes of EHEC, the RD educated students about simple substitutions that could be made each day to improve the nutritional content of their meals and snacks. For example, choosing low-fat or fat free milk instead of whole milk, 100 percent fruit juices instead of soda, and opting for sherbet, yogurt or fruit instead of cake, cookies or ice cream. The $\mathrm{RD}$ also touched on the importance of balancing energy intake with energy expenditure. EHEC ended with a brief discussion of the types of physical activity opportunities on campus.

The RD then gave each student a packet of handouts with more detailed information designed to reinforce the nutrition information discussed in EHEC. These handouts were obtained through UConn Student Health Services' Nutrition Office and included "Nutrition 101," which included basic nutrition facts, My Pyramid (http://www.mypyramid. gov/), "Seven Ways to Size up Your Serving," which provided tips on estimating portion size (National Dairy Council@1996, Rosemont, IL), "Healthy Eating Tips for the Dining Hall," and "Tips for Healthy Snacking" which included examples of sample meals and snacks.

\section{Statistical Analysis}

We computed descriptive statistics on all study variables. The Wilcoxin Signed Rank Test was used to examine differences within the EHEC intervention and comparison groups separately, pre- to post-EHEC. Mann-Whitney U tests were conducted to determine if there were differences between the EHEC intervention and comparison groups on pre- to post-EHEC difference scores on the outcome variables. To examine group equivalence on demographic variables, an independent samples t-test was conducted to test for age differences between the intervention and comparison groups. Also, chi-square tests of independence were used to examine sex and ethnicity differences between the intervention and comparison groups. Data were analyzed using the SPSS statistical package (Version 
16.0) with $\mathrm{p}<0.05$ as the level of statistical significance.

\section{Results}

\section{Sample}

Subjects enrolled included 319 students (182 Female), with a mean age of 19.0 years \pm 1.0 year. Of these, 77.8 percent self-disclosed themselves as Caucasian, 12.2 percent African American, 6.0 percent Asian, and 2.2 percent Hispanic. There were 166 students in the EHEC intervention group (51.2 percent from the dormitory and 48.8 percent from the classroom), and 153 students in the comparison group (54.2 percent from the dormitory and 45.8 percent from the classroom) (Figure 1).

In the pre and post surveys, students were asked to provide the last letter of their last name, the day of the month in which they were born, and the last digit of their social security number. This information was used to match each participant's pre and post survey.

Of the 166 assigned to EHEC, 103 completed the study (40.8 percent from the dormitory and 59.2 percent from the classroom setting). Of the 153 students assigned to the comparison group, 118 students completed the study (47.5 percent from the dormitory and 52.5 percent from the classroom setting). Thus, the overall study attrition rate was 30.7 percent. More students in EHEC (38.0 percent) did not complete the study than students in the comparison group (22.9 percent $)(Z=-2.911, p<0.01)$. Finally, a greater percentage of students residing in the dormitories (41.7 percent) did not complete the study than those from the classroom (17.7 percent $)(Z=-4.463, p<0.01)$.

The study sample, post-attrition, reflected the demographics of the larger university population, with 57.0 percent of our sample versus 52.0 percent of the university identifying as female and 20.2 percent of our sample versus 19.0 percent of the university identifying as minority (UConn fact sheet, n.d.). Post-attrition, there was no significant difference in age between the comparison and intervention groups
$(\mathrm{F}=1.475, \mathrm{p}>0.05)$. Post-attrition, significant differences in ethnicity $(\chi 2(2)=11.325, \mathrm{p}<$ $0.05)$ and sex $(\chi 2(2)=4.996, p<0.05)$ existed between the intervention and comparison groups.

\section{Within EHEC and Comparison Group Findings}

\section{EHEC}

The responses of participants in the EHEC intervention group to the DHKS pre- and postEHEC are shown in Table 1. Significant improvements in attitude were seen for factors (1) and (3). Participants indicated six significant improvements in response to factor (1) perceived value of healthy eating. These included an increase in percent of students that viewed the importance of: 1) using salt in moderation as somewhat to very important $(\mathrm{Z}=$ $-2.772, \mathrm{p}<0.01)$; 2) using sugars in moderation as somewhat to very important $(\mathrm{Z}=-1.968, \mathrm{p}<$ $0.05) ; 3$ ) choosing a diet low in saturated fat as somewhat to very important $(Z=-2.772, p<$ $0.01)$; 4) choosing a diet with adequate fiber intake as somewhat to very important $(\mathrm{Z}=$ 2.254, $\mathrm{p}<0.05)$; 5) choosing a diet with a variety of foods as somewhat to very important $(\mathrm{Z}=-2.145, \mathrm{p}<0.05)$; and 6$)$ choosing a diet with plenty of breads, cereals, rice and pasta as somewhat to very important $(Z=-3.355, \mathrm{p}<$ 0.01). One significant improvement was observed in factor (3), perception of adequacy of intake, with an increase in the percent of students who reported consuming low fat luncheon meats sometimes to always $(\mathrm{Z}=$ 2.911, $\mathrm{p}<0.01)$. Significant improvements in behavior were seen only for factor (11), avoidance of extra fat, where there was an increase in percent of students who reported removing the skin from chicken prior to consumption sometimes to always $(Z=-2.758, p$ $<0.01)$. No significant differences in response to the DHKS pre- to post-EHEC were observed in factors (5), (6), or (12) $(\mathrm{p}>0.05)$

\section{EHEC Dormitory Setting}

Among the 42 students in the EHEC dormitory setting, participants indicated two significant differences in attitude seen in responses to factor (1) perceived value of healthy eating. These 
included an increase in the percent of students that viewed the importance of: 1) choosing a diet low in salt from 11.9 percent to 23.8 percent for very important, 45.2 percent to 52.4 percent for somewhat important, 21.4 percent to 11.9 percent for not too important, and 21.4 percent to 11.9 percent for not at all important $(\mathrm{Z}=-2.4$, $\mathrm{p}<0.05)$; and 2) choosing a diet low in saturated fat from 19.0 percent to 38.1 percent for very important, 50 percent to 42.9 percent for somewhat important, 23.8 percent to 14.3 percent for not too important, and 7.1 percent to 4.8 percent for not at all important $(\mathrm{Z}=-3.13, \mathrm{p}$ $<0.01)$. One behavioral difference was noted in factor (3), with the percent of students who reported consumption of lower fat luncheon meats changed from 9.5 percent to 26.2 percent for always, 38.1 percent to 23.8 percent for sometimes, 33.3 percent to 23.8 percent for rarely, and 19.0 percent to 11.9 percent for never $(\mathrm{Z}=-2.4, \mathrm{p}<0.01)$. One behavioral difference was noted in factor (11) with the percent of students who reported removing the skin from chicken prior to eating changed from 41.5 percent to 45.2 percent for always, 24.4 percent to 33.3 percent for sometimes, 17.1 percent to 9.5 percent for rarely, and 17.1 percent to 11.9 percent for never $(Z=-2.054, p<0.05)$. No significant differences were seen in factors (5) (6) or (12) $(\mathrm{p}>0.05)$.

\section{EHEC Classroom Setting}

Among the 61 students in the EHEC classroom setting, four significant differences were found in attitude seen in responses to factor (1). These included changes in the percent of students who reported the importance of choosing a diet as follows: 1) that is low in salt changed from 19.7 percent to 24.6 percent for very important, 45.9 percent to 50.8 percent for somewhat important, 29.5 percent to 19.7 percent for not too important, and with no change for not at all important $(Z=-1.964, p<0.05) ; 2)$ has adequate fiber changed from 16.4 percent to 19.7 percent for very important, no change for somewhat important, 32.8 percent to 41 percent for not too important, and 18 percent to 6.6 percent for not at all important $(\mathrm{Z}=-2.117, \mathrm{p}<0.05) ; 3)$ has a variety of foods changed from 29.5 percent to 47.5 percent for very important, 50.8 percent to 42.6 percent for somewhat important, 18 percent to 9.8 percent for not too important, and 1.6 percent to 0 percent for not at all important $(\mathrm{Z}=$ $-2.753, p<0.01)$; and 4) has plenty of breads, rice, cereals and pasta changed from 19.7 percent to 32.2 percent for very important, 45.9 percent to 47.5 percent for somewhat important, 31.1 percent to 20.3 percent for not too important, and 3.3 percent to 0 percent for not at all important $(Z=-3.272, p<0.01)$. No significant differences were seen in factors (3) (5) (6) (11) or (12) $(\mathrm{p}>0.05)$.

\section{THE EHEC Comparison Group (Table 2)}

Results of the overall response of the EHEC comparison group to the DHKS pre- to postEHEC are shown in Table 2. There were no significant differences in response pre and postEHEC for any of the six DHKS factors ( $p>$ $0.05)$.

\section{EHEC versus Comparison between Group Findings}

For the attitudinal DHKS factor (1) perceived value of healthy eating, a greater percent of students in the EHEC group reported the importance of using salt in moderation compared to the comparison group, 27.2 percent versus 10.2 percent, respectively $(Z=-3.078, p$ $<0.01$ ). In addition, for behavioral factor (3) consumption of low-fat / low-calorie foods, 33 percent of students in the EHEC group reported consuming lower fat luncheon meats compared to 3.4 percent of students in the comparison group $(Z=-2.577, p<0.01)$. No significant differences were found between groups for factors (5), (6), (11), or (12) ( $\mathrm{p}>0.05)$.

\section{EHEC Dormitory versus Classroom between Setting Findings}

For attitudinal factor (1) perceived value of healthy eating, a greater percent of students in the EHEC classroom setting reported the importance of eating a variety of foods compared to the dormitory setting, 19.1 percent versus 37.7 percent of students, respectively ( $\mathrm{Z}$ $=-2.256, \mathrm{p}<0.05)$. No significant differences were found between settings for factors (3), (5) (6), (11), or (12) $(\mathrm{p}>0.05)$. 


\section{Discussion}

This pilot study demonstrated that a one-time, one-hour, focused nutrition education program appeared to favorably influence college students' perceived value of healthy eating. Improvements in DHKS responses for the EHEC group were seen in factor (1) perceived value of healthy eating for the importance of using salt and sugars in moderation, and choosing a diet that is low in saturated fat and has adequate fiber, and has a variety of foods and plenty of breads, cereals, rice and pasta. In addition, improvements were noted in factor (3) perception of adequacy of intake with an increase in the percent of students who reported consuming low fat luncheon meats; and in factor (11) avoidance of extra fat with an increase in the percent of students who reported removing the skin from chicken prior to consumption. In contrast, no significant differences were found in DHKS responses from pre- to post-EHEC intervention among the comparison group.

Of note, students in the EHEC differed from those in the comparison group regarding their post-test responses to DHKS factor (1) perceived value of healthy eating, with more students in the EHEC group reporting the importance of using salt in moderation. Students in the EHEC and comparison groups also differed in their DHKS response to factor (3) consumption of low fat/low calorie foods, with more students in the EHEC group reporting consuming lower fat luncheon meats than students in the comparison group. More students in the EHEC classroom setting reported the importance of eating a variety of foods than those in the dormitory setting. Therefore, the classroom appeared to be the more effective setting for facilitating positive changes in students' perceived value of healthy eating compared to the dormitory setting.

The most favorable improvements in DHKS response were seen in factor (1) for the EHEC group. These results suggest that a brief college nutrition education program that encourages healthy eating and incorporates meal strategies may positively influence students' perceived value of healthy eating. However, this favorable change in perceived value of healthy eating did not always translate into positive eating behavior changes as noted by little to no change in factors (3) (6) (11) and (12). These findings are consistent with evidence that nutrition knowledge does not always lead to behavior change (Hoelsher, Parcel, \& Kelder, 2002; Reynolds, Raczynski, \& Binkey, 1998). Other reasons for not finding indications in behavior change following EHEC could be that EHEC was not long and intensive enough as compared to other programs in the literature that consisted of classroom interventions and workshops ranging from 8 weeks to an entire semester (Abood, Black, \& Birnbaum, 2004; Matvienko et al., 2001). Also,EHEC did not include alternate modes of nutrition education delivery, such as on-line programming, that may be more effective in promoting positive behavior changes in a young population such as ours (Casazza \& Ciccazzo, 2006).

Major strengths of this study were that the nutrition education intervention was designed and implemented by RDs, and the DHKS is a valid and reliable assessment of dietary perception and behavior. The instrument possesses content validity, discriminant validity, convergent validity, correspondence validity and internal reliability (Obayashi et al., 2003).

\section{Limitations}

Limitations to note include students in the dormitory setting self-selected attending the nutrition program, whereas students in the classroom setting attended class as usual, and stayed to receive the nutrition program if they wished. Students residing in dormitories who selected to participate in the EHEC may have had an increased interest in nutrition compared to those who chose not to participate in EHEC. A second limitation is that the DHKS instrument is valid and reliable for Americans ages 20 and over, but the participants in this study have a mean age of 19. However, because the age range of the participants in this study was 18-24, and since the standard deviation for age was 1 year, overlap existed between the two populations. The validation population had a similar racial/ethnic composition to the participants in this study, with the majority self-identifying as 
Caucasian. A third limitation is that, although the study sample was representative of the larger University population in terms of ethnic affiliation, Caucasian and female students were overrepresented. Moreover, the demographic information was not collected in the pretest, and thus the demographic composition of those participants who did not complete the study is unknown. Future research should examine differences among nutrition knowledge and diet consumption among college students by race, sex, and ethnicity.
Another limitation is that nothing was done to control for possible contamination effects of comparison participants learning about the intervention through participants in the intervention group. Lastly, the overall attrition rate of 30 percent may have been reduced by inclusion of participation incentives. Further study with brief nutrition intervention programs targeting college students is warranted to confirm our findings. Continued efforts to promote healthy dietary behaviors among college students should be a main focus for health professionals.

\section{References}

Abood D.A., Black D.R., \& Birnbaum R.D. (2004). Nutrition education intervention for college female athletes. Journal of Nutrition Education \& Behavior, 36, 135-139.

Anderson D.A., Shapiro J.R., \& Lundgren J.D. (2003). The freshman year of college as a critical period of weight gain: An initial evaluation. Eating Behaviors, 4, 363-367.

Camelon K.M., Hadell K., Jamsen P.T., Ketonen K.J., Kohtamaki H.M., Makimatilla S., Tormala M.L., \& Valve R.H. (1998). The plate model: A visual method of teaching meal planning. Journal of American Dietetic Association, 98, 1155-1158.

Casazza K., \& Ciccazzo M. (2006). Improving the dietary patterns of adolescents using a computer-based approach. Journal School Health, 76, 43-46.

Clement J.M., Schmidt C.A., Bernaix L.W., Covington N.K., \& Carr T.R. (2004). Obesity and physical activity in college women: Implications for clinical practice. Journal of American Academic Nurse Practitioners, 16, 291-299.

Collison S.B., Kuczmarski M.F., \& Vickery C.E. (1996). Impact of nutrition education on female athletes. American Journal of Health Behavior, 20, 270-289.

Conklin M.T., Cranage D.A., \& Lambert C.U. (2005). College students' use of point of selection nutrition information. Topics in Clinical Nutrition, 20, 97-108.

Delinsky S.S., \& Wilson G.T. (2008). Weight gain, dietary restraint, and disordered eating in the freshman year of college. Eating Behaviors, 9, 82-90.

Healthy campus 2010: Making it happen task force on national health objectives. (n.d.). Retrieved April 1, 2008, from http://www.acha.org/Info_resources/Powerpoint/hc2010_am00.ppt

Hoelsher D.M., Evans A., Parcel G.S., \& Kelder S.H. (2002). Designing effective nutrition interventions for adolescents. Journal of American Dietetic Association, 102, 52-63.

Hoffman D.J., Policastro P., Quick V., \& Lee S. (2006). Changes in body weight and fat mass of men and women in the first year of college: A study of the "Freshman 15." Journal of American College Health, 55, 41-45.

Kolb. D. A., \& Fry, R. (1975). Toward an applied theory of experiential learning. In C. Cooper (Ed.), Theories of group process (pp. 153-171). New York: John Wiley and Sons, Inc.

Kolodinsky J., Harvey-Berino J.R., Berlin L., Johnson R., \& Reynolds T.W. (2007). Knowledge of current dietary guidelines and food choice by college students: Better eaters have higher knowledge of dietary guidance. Journal of American Dietetic Association, 107, 1409-1413.

Kubena K., \& Carson D. (1988). Nutrition promotion in a university foodservice: reduced fat, sodium, and energy content of menus. Journal of American Dietetic Association, 88, 1412-1416.

Matvienko O., Lewis D.S., \& Schafer E. (2001). A college nutrition science course as an intervention to prevent weight gain in female college freshman. Journal of Nutrition Education, 33, 95-101. 
Mazier M.J.P., \& McLeod S.L. (2007). University science students' knowledge of fats. Canadian Journal of Dietetic Practice and Research, 68, 154-159.

Misra R. (2007). Knowledge, attitudes, and label use among college students. American Dietetic Association, 107, 2130-2134.

Obayashi S., Bianchi L.J., \& Song W.O. (2003). Reliability and validity of nutrition knowledge, socialpsychological factors, and food label use scales from the 1995 Diet and Health Knowledge Survey. Journal of Nutrition Education, 35, 83-92.

Reynolds K.D., Raczynski J.M., \& Binkey D. (1998). Design of 'High-5': a school-based study to promote fruit and vegetable consumption. Journal of Cancer Education, 13, 169-77.

Sapp S.G., \& Jensen H.H. (1997). Reliability and validity of nutrition knowledge and diet-health awareness tests developed from 1989-1991 Diet and Health Knowledge Surveys. Journal of Nutrition Education, 29, 63-72.

The American College Health Association. (2007). National College Health Assessment Fall 2007 Reference Group Data Report. Journal of American College Health, 53, 195-206.

UConn fact sheet. (n.d.). Retrieved May 7, 2008, from http://www.uconn.edu/about/pdf_factsheets/ UConn_Facts_2008.pdf

U.S. Department of Agriculture. (1995). What we eat in America: 1994-1996, Diet and Health Knowledge Survey Questionnaire.

U.S. Department of Health and Human Services and U.S. Department of Agriculture. (2005). Dietary guidelines for Americans.

York-Crowe E.E., White M.A., Paeratakul S., \& Williamson D. (2006). The diet and health knowledge survey: Development of a short interview format. Eating Behaviors, 7, 235-242.

Author Information

Linda S. Pescatello, PhD*

Professor,University of Connecticut

Department of Kinesiology

Human Performance Laboratory, Neag School of Education

2095 Hillside Road, U-1110

Storrs, CT 06269-1110

Tel: (860) 486-0008, Fax: (860) 486-1123

E-mail: Linda.Pescatello@uconn.edu

Geraldine Napoleone Pires, MS, RD, CHES

University of Connecticut

Department of Allied Health Sciences

Amy Pumerantz, MA, RD

University of Connecticut

Student Health Services

Lawrence K. Silbart, PhD

University of Connecticut

Department of Allied Health Sciences

* corresponding author 
Appendix A

Figure 1. Study Design Overview
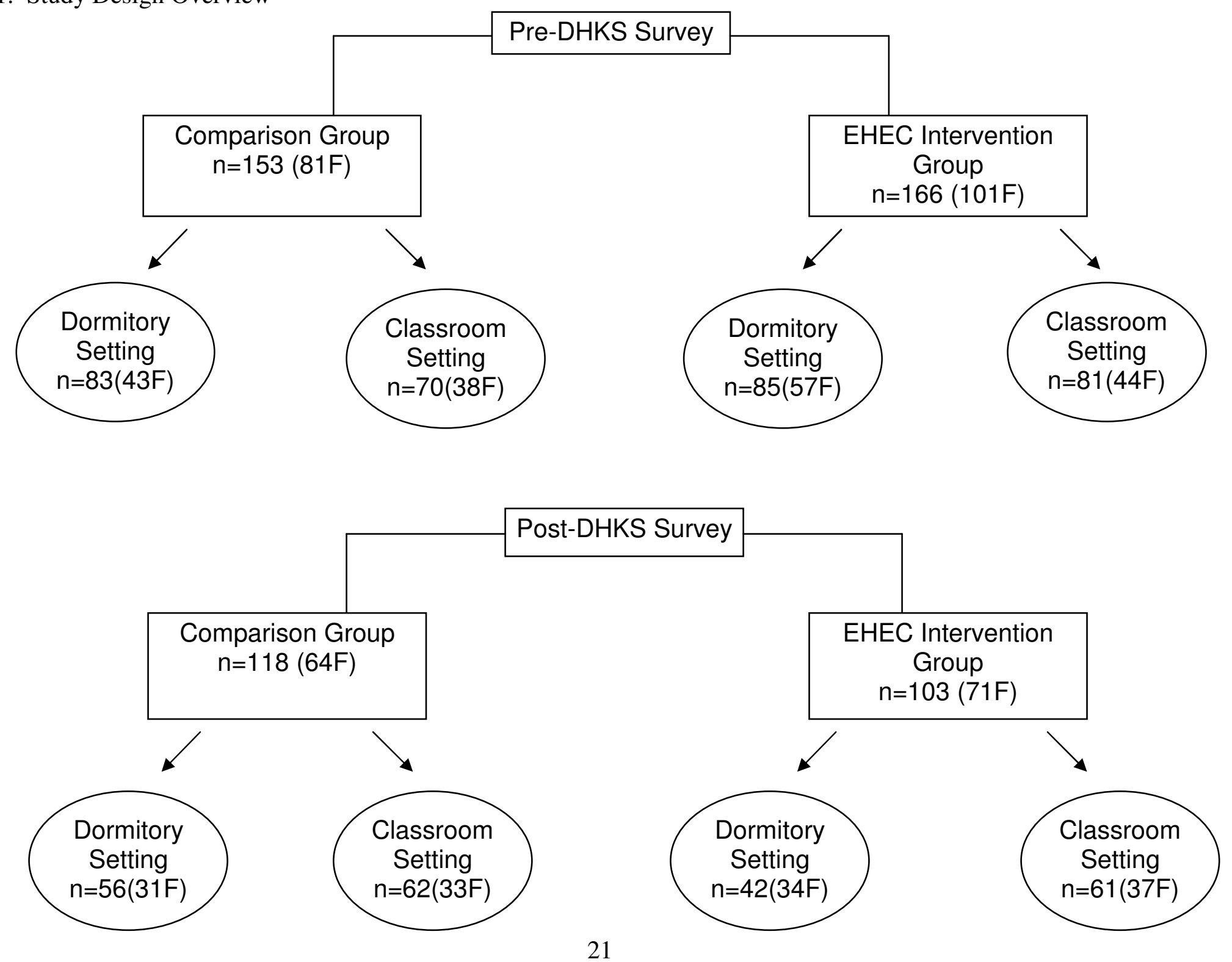
Factor 1: Perceived Value of Healthy Eating

To you personally, how important is it to:

a) Use salt or sodium only in moderation?**

Very Important

Somewhat Important

\begin{tabular}{ll} 
Pre & Post \\
\hline 16.5 & 24.3
\end{tabular}

$45.6 \quad 51.5$

$26.2 \quad 17.0$

$11.1 \quad 7.1$

Not At All Important

fat?**

b) Choose a diet low in saturated fat?

$\begin{array}{llll} & \text { Pre } & \text { Post } & \text { Pre- to Post-EHEC Change } \\ \text { Very Important } & 22.3 & 32.0 & 9.7 \\ \text { Somewhat Important } & 44.7 & 43.7 & -1.0 \\ \text { Not Too Important } & 25.2 & 18.0 & -6.8 \\ \text { Not At All Important } & 7.8 & 5.8 & -2.0\end{array}$

c) Choose a diet with plenty of fruits and vegetables?

\begin{tabular}{llll} 
& Pre & Post & Pre- to Post-EHEC Change \\
\cline { 2 - 4 } Very Important & 50.5 & 54.4 & 3.9 \\
Somewhat Important & 37.9 & 39.8 & 1.9 \\
Not Too Important & 9.7 & 4.9 & -4.8 \\
Not At All Important & 1.9 & 1.0 & -0.9
\end{tabular}

d) Use sugars only in moderation?*

\begin{tabular}{lll} 
Pre & Post & Pre- to Post-EHEC Change \\
\hline 20.2 & 27.2 & 6.8 \\
48.5 & 49.5 & 1.0 \\
23.3 & 21.4 & -1.9 \\
6.8 & 1.9 & -4.9
\end{tabular}

Very Important

Somewhat Important

Not Too Important

Not At All Important

e) Choose a diet with adequate fiber?*

Very Important

Pre Post Pre- to Post-EHEC Change

Somewhat Important

Not Too Important

$18.4 \quad 25.2$

$40.8 \quad 39.7$

6.8

$\begin{array}{lll}29.1 & 31.1 & 2.0\end{array}$

Not At All Important

$\begin{array}{lll}11.7 & 5.8 & -5.9\end{array}$

*pre- vs. post-EHEC, $\mathrm{p}<0.05$; **pre- vs. post-EHEC, $\mathrm{p}<0.01$ f) Eat a variety of foods?

Very Important

Somewhat Important

Not Too Important

Not At All Important

$\begin{array}{lll}\text { Pre } & \text { Post } & \text { Pre- to Post- EHEC Change } \\ 41.7 & 50.5 & 8.8 \\ 41.7 & 39.8 & -1.9 \\ 15.5 & 9.7 & -5.8 \\ 1.0 & 0.0 & -1.0\end{array}$

g) Maintain a healthy weight?

Very Important

Somewhat Important

Not Too Important

Not At All Important

\begin{tabular}{lll} 
Pre & Post & Pre- to Post- EHEC Change \\
\hline 70.9 & 69.9 & -1.0 \\
24.3 & 27.2 & 2.9 \\
2.9 & 1.0 & -1.9 \\
1.9 & 1.9 & 0.0
\end{tabular}

h) Choose a diet low in fat?

Very Important

Somewhat Important

Not Too Important

Not At All Important

\begin{tabular}{lll} 
Pre & Post & Pre- to Post- EHEC Change \\
\hline 33 & 36.9 & 3.9 \\
39.8 & 40.8 & 1.0 \\
23.3 & 17.5 & -5.8 \\
3.9 & 4.9 & 1.0
\end{tabular}

i) Choose a diet low in cholesterol?

Very Important

Pre Post Pre- to Post- EHEC Change

Somewhat Important

Not Too Important

$\begin{array}{lll}26.2 & 27.2 & 1.0\end{array}$

$\begin{array}{lll}31.1 & 37.9 & 6.8\end{array}$

Not At All Important

$\begin{array}{lll}36.9 & 32.0 & -4.9\end{array}$

$3.9 \quad 4.9 \quad-0.9$

k) Choose a diet with plenty of breads, cereals, rice, and pasta? $* *$

Very Important Pre Post Pre- to Post-EHEC Change

Somewhat Important

Not Too Important

Not At All Important

$\begin{array}{lll}45.6 & 48.5 & 2.9\end{array}$

$\begin{array}{lll}27.2 & 17.5 & -9.7\end{array}$

$\begin{array}{lll}2.9 & 0.0 & -2.9\end{array}$




Factor 3: Consumption of low-fat/low-calorie foods
How often would you say you:

a) Eat lower-fat luncheon meats instead of regular luncheon meats?**

$\begin{array}{llll} & \text { Pre } & \text { Post } & \text { Pre- to Post-EHEC Change } \\ \text { Always } & 0.7 & 19.4 & 8.7 \\ \text { Sometimes } & 39.8 & 44.7 & 4.9 \\ \text { Rarely } & 33.0 & 23.3 & -9.7 \\ \text { Never } & 15.5 & 12.6 & -2.9\end{array}$

b) Use skim or 1 percent milk instead of 2 percent or whole milk?

\begin{tabular}{llll} 
& Pre & Post & Pre- to Post-EHEC Change \\
\cline { 2 - 4 } Always & 55.3 & 53.4 & -1.9 \\
Sometimes & 21.4 & 23.3 & 1.9 \\
Rarely & 10.7 & 15.0 & 4.3 \\
Never & 12.6 & 8.7 & -3.9
\end{tabular}

c) Eat special, low-fat cheeses, when you eat cheese?

\begin{tabular}{llll} 
& Pre & Post & Pre- to Post-EHEC Change \\
\cline { 2 - 4 } Always & 7.8 & 7.8 & 0.0 \\
Sometimes & 29.1 & 36.9 & 7.8 \\
Rarely & 39.8 & 35.0 & -4.8 \\
Never & 23.3 & 20.0 & -3.3
\end{tabular}

d) Eat ice milk, frozen yogurt, or sherbet instead of ice cream?

$\begin{array}{lcll} & \text { Pre } & \text { Post } & \text { Pre- to Post-EHEC Change } \\ \text { Always } & 9.7 & 9.7 & 0.0 \\ \text { Sometimes } & 33.0 & 43.7 & 10.7 \\ \text { Rarely } & 35.9 & 32.0 & -3.9 \\ \text { Never } & 20.4 & 14.6 & -5.8\end{array}$

e) Use low-calorie instead of regular salad dressing?

\begin{tabular}{llll} 
& Pre & Post & Pre- to Post-EHEC Change \\
\cline { 2 - 4 } Always & 26.2 & 25.2 & 1.0 \\
Sometimes & 39.8 & 47.6 & 7.8 \\
Rarely & 16.5 & 15.5 & -1.0 \\
Never & 16.5 & 11.7 & -4.8 \\
& & & \\
** pre- vs. post-EHEC, $\mathrm{p}<0.01$ & & &
\end{tabular}

Factor 11: Avoidance of Extra Fats

a) When you eat chicken, how often do you eat it fried?

\begin{tabular}{|c|c|c|c|c|}
\hline & & Pre & Post & Pre- to Post-EHEC Change \\
\hline Never & & 10.7 & 12.6 & 1.9 \\
\hline Rarely & & 40.8 & 36.9 & -3.9 \\
\hline Sometimes & & 45.6 & 49.5 & 3.9 \\
\hline Always & 1.0 & 1.0 & 0.0 & \\
\hline
\end{tabular}

b) When you eat chicken, how often do you remove the skin?**

\begin{tabular}{|c|c|c|c|c|}
\hline & & Pre & Post & Pre- to Post-EHEC Change \\
\hline Never & & 20.4 & 17.5 & -2.9 \\
\hline Rarely & & 23.3 & 14.6 & -8.7 \\
\hline Sometimes & & 30.1 & 39.8 & 9.7 \\
\hline Always & 24.3 & 28.2 & 3.9 & \\
\hline
\end{tabular}

c) When you eat meat and there is visible fat, how often do you trim the fat?

\begin{tabular}{|c|c|c|c|c|}
\hline & & Pre & Post & Pre- to Post-EHEC Change \\
\hline Never & & 3.9 & 3.9 & 0.0 \\
\hline Rarely & & 6.8 & 9.7 & 2.9 \\
\hline Sometimes & & 19.4 & 20.1 & 1.0 \\
\hline Always & 68.0 & 66.0 & -2.0 & \\
\hline
\end{tabular}

**pre- vs. post-EHEC, $\mathrm{p}<0.01$ 
Table 2: Pre-to Post- DHKS Responses by percent of Students Responding Within the EHEC Comparison Group (n=118)

Factor 1: Perceived Value of Healthy Eating

To you personally, how important is it to:

\begin{tabular}{|c|c|c|c|}
\hline \multicolumn{4}{|c|}{ a) Use salt or sodium only in moderation? } \\
\hline & Pre & Post & Pre- to Post-DHKS Change \\
\hline Very Important & 16.9 & 18.0 & 0.9 \\
\hline Somewhat Important & 46.6 & 47.5 & 0.9 \\
\hline Not Too Important & 25.4 & 23.7 & -1.7 \\
\hline Not At All Important & 11.0 & 11.0 & 0.0 \\
\hline \multicolumn{4}{|c|}{ b) Choose a diet low in saturated fat? } \\
\hline & Pre & Post & Pre- to Post-DHKS Change \\
\hline Very Important & 22.0 & 27.0 & 5.1 \\
\hline Somewhat Important & 31.4 & 27.1 & -4.3 \\
\hline Not Too Important & 37.3 & 39.0 & 1.7 \\
\hline Not At All Important & 9.3 & 6.8 & -2.5 \\
\hline
\end{tabular}

c) Choose a diet with plenty of fruits and vegetables?

$\begin{array}{llll} & \text { Pre } & \text { Post } & \text { Pre- to Post-DHKS Change } \\ \text { Very Important } & 38.1 & 38.0 & 0.0 \\ \text { Somewhat Important } & 47.5 & 44.1 & -3.4 \\ \text { Not Too Important } & 11.0 & 16.9 & 5.9 \\ \text { Not At All Important } & 3.4 & 0.8 & -2.6\end{array}$

d) Use sugars only in moderation?

$\begin{array}{llll} & \text { Pre } & \text { Post } & \text { Pre- to Post-DHKS Change } \\ \text { Very Important } & 15.3 & 12.0 & -3.4 \\ \text { Somewhat Important } & 43.2 & 57.6 & 14.4 \\ \text { Not Too Important } & 34.7 & 25.4 & -9.3 \\ \text { Not At All Important } & 6.8 & 5.1 & -1.7\end{array}$

e) Choose a diet with adequate fiber?

$\begin{array}{llll} & \text { Pre } & \text { Post } & \text { Pre- to Post-DHKS Change } \\ \text { Very Important } & 12.7 & 13.0 & 0.3 \\ \text { Somewhat Important } & 31.4 & 42.4 & 11.0 \\ \text { Not Too Important } & 48.3 & 39.0 & -9.3 \\ \text { Not At All Important } & 7.6 & 5.9 & -1.7\end{array}$

\begin{tabular}{|c|c|c|c|}
\hline \multicolumn{4}{|c|}{ f) Eat a variety of foods? } \\
\hline & Pre & Post & Pre- to Post- DHKS Change \\
\hline Very Important & 39.8 & 36.0 & -4.2 \\
\hline Somewhat Important & 43.2 & 46.6 & 3.4 \\
\hline Not Too Important & 14.4 & 16.9 & 2.5 \\
\hline Not At All Important & 2.5 & 0.8 & -1.7 \\
\hline \multicolumn{4}{|c|}{ g) Maintain a healthy weight? } \\
\hline & Pre & Post & Pre- to Post- DHKS Change \\
\hline Very Important & 64.4 & 61.0 & -3.4 \\
\hline Somewhat Important & 31.4 & 31.4 & 0.0 \\
\hline Not Too Important & 4.2 & 6.8 & 2.6 \\
\hline Not At All Important & 0.0 & 0.8 & 0.8 \\
\hline \multicolumn{4}{|c|}{ h) Choose a diet low in fat? } \\
\hline & Pre & Post & Pre- to Post- DHKS Change \\
\hline Very Important & 15.3 & 19.5 & 4.2 \\
\hline Somewhat Important & 47.5 & 44.9 & -2.6 \\
\hline Not Too Important & 25.4 & 23.7 & -1.7 \\
\hline Not At All Important & 11.9 & 11.9 & 0.0 \\
\hline \multicolumn{4}{|c|}{ i) Choose a diet low in cholesterol? } \\
\hline & Pre & Post & Pre- to Post- DHKS Change \\
\hline Very Important & 16.9 & 19.0 & 1.7 \\
\hline Somewhat Important & 30.5 & 38.1 & 7.6 \\
\hline Not Too Important & 38.1 & 31.4 & -6.7 \\
\hline Not At All Important & 14.0 & 11.9 & -2.5 \\
\hline \multicolumn{4}{|c|}{ k) Choose a diet with plenty of breads, cereals, rice, and pasta? } \\
\hline & $\underline{\text { Pre }}$ & Post & Pre- to Post-DHKS Change \\
\hline Very Important & 17.8 & 13.6 & -4.2 \\
\hline Somewhat Important & 41.5 & 51.7 & 10.2 \\
\hline Not Too Important & 32.2 & 29.7 & -2.5 \\
\hline Not At All Important & 8.5 & 5.1 & -3.4 \\
\hline
\end{tabular}




Factor 3: Consumption of low-fat/low-calorie foods
How often would you say you:

a) Eat lower-fat luncheon meats instead of regular luncheon meats?

\begin{tabular}{llll} 
& Pre & Post & Pre- to Post-EHEC Change \\
\cline { 2 - 4 } Always & 5.9 & 5.9 & 0.0 \\
Sometimes & 41.5 & 37.3 & -4.2 \\
Rarely & 29.7 & 35.6 & 5.9 \\
Never & 20.0 & 21.2 & 1.7
\end{tabular}

b) Use skim or 1 percent milk instead of 2 percent or whole milk?

\begin{tabular}{llll} 
& Pre & Post & Pre- to Post-EHEC Change \\
\cline { 2 - 4 } Always & 49.2 & 47.2 & -2.6 \\
Sometimes & 19.5 & 19.5 & 0.0 \\
Rarely & 14.4 & 17.8 & 3.4 \\
Never & 16.0 & 16.0 & 0.0
\end{tabular}

c) Eat special, low-fat cheeses, when you eat cheese?

$\begin{array}{llll} & \text { Pre } & \text { Post } & \text { Pre- } \\ \text { Always } & 4.2 & 5.1 & 0.9 \\ \text { Sometimes } & 24.6 & 20.3 & -4.3 \\ \text { Rarely } & 30.5 & 44.1 & 13.6 \\ \text { Never } & 39.0 & 29.7 & -9.3\end{array}$

d) Eat ice milk, frozen yogurt, or sherbet instead of ice cream?

\begin{tabular}{llll} 
& Pre & Post & Pre- to Post-EHEC Change \\
\cline { 2 - 4 } Always & 3.4 & 1.7 & -1.7 \\
Sometimes & 25.4 & 23.7 & -1.7 \\
Rarely & 44.1 & 46.6 & 2.5 \\
Never & 27.1 & 28.0 & 0.9
\end{tabular}

e) Use low-calorie instead of regular salad dressing?

\begin{tabular}{llll} 
& Pre & Post & Pre- to Post-EHEC Change \\
\cline { 2 - 4 } Always & 18.6 & 20.0 & 1.4 \\
Sometimes & 28.0 & 23.7 & -4.3 \\
Rarely & 25.4 & 33.9 & 8.5 \\
Never & 25.0 & 22.9 & -2.5
\end{tabular}

**pre- vs. post-EHEC, $\mathrm{p}<0.01$
Factor 11: Avoidance of Extra Fats

a) When you eat chicken, how often do you eat it fried?

$\begin{array}{llll} & \text { Pre } & \text { Post } & \text { Pre- to Post-EHEC Change } \\ \text { Never } & 10.7 & 5.9 & -4.8 \\ \text { Rarely } & 40.8 & 30.5 & -10.3 \\ \text { Sometimes } & 45.6 & 52.5 & 6.9 \\ \text { Always } & 1.0 & 6.8 & 5.8\end{array}$

b) When you eat chicken, how often do you remove the skin?

$\begin{array}{llll} & \text { Pre } & \text { Post } & \text { Pre- to Post-EHEC Change } \\ \text { Never } & 20.4 & 16.9 & -3.5 \\ \text { Rarely } & 23.3 & 22.9 & -0.4 \\ \text { Sometimes } & 30.1 & 33.9 & 3.8 \\ \text { Always } & 24.3 & 22.0 & -2.3\end{array}$

c) When you eat meat and there is visible fat, how often do you trim the fat?

$\begin{array}{llll} & \text { Pre } & \text { Post } & \text { Pre } \\ \text { Never } & 3.9 & 5.1 & 1.2 \\ \text { Rarely } & 6.8 & 8.5 & 1.7 \\ \text { Sometimes } & 19.4 & 22.9 & 3.5 \\ \text { Always } & 68.0 & 59.3 & -8.7\end{array}$

***pre- vs. post-EHEC, $\mathrm{p}<0.01$ 